\title{
Change in grip strength in trans people and its association with lean body mass and bone density
}

\author{
Miranda Scharff1,*, Chantal Maria Wiepjes ${ }^{1, *}$, Maartje Klaver ${ }^{1}$, Thomas Schreiner ${ }^{2}$, Guy T'Sjoen ${ }^{3}$ and \\ Martin den Heijer ${ }^{1}$
}

${ }^{1}$ Department of Endocrinology and Center of Expertise on Gender Dysphoria, Amsterdam University Medical Center, Vrije Universiteit, Amsterdam, the Netherlands

${ }^{2}$ Department of Endocrinology, Oslo University Hospital, Oslo, Norway

${ }^{3}$ Department of Endocrinology \& Center for Sexology and Gender, Ghent University Hospital, Ghent, Belgium

Correspondence should be addressed to M den Heijer: m.denheijer@amsterdamumc.nl

*(M Scharff and C M Wiepjes contributed equally to this work)

\begin{abstract}
Objective: Gender-affirming hormonal treatment (HT) in trans people changes physical appearance. Muscle mass and strength are important aspects of physical appearance, but few data exist on the effect of HT on grip strength and muscle mass. This study aimed to investigate the change in grip strength in trans people during the first year of $\mathrm{HT}$ and to study the possible determinants of this change and the associations between changes in grip strength, lean body mass and bone mineral density (BMD).

Design and methods: A multicenter, prospective study was performed, including 249

transwomen and 278 transmen. Grip strength, lean body mass and BMD were measured at baseline and after 1 year.

Results: After 1 year of $\mathrm{HT}$, grip strength decreased with $-1.8 \mathrm{~kg}(95 \% \mathrm{Cl}-2.6 ;-1.0)$ in transwomen and increased with $+6.1 \mathrm{~kg}(95 \% \mathrm{Cl}+5.5 ;+6.7)$ in transmen. No differences in grip strength change was found between age groups, BMI groups, hormonal administration routes or hormone concentrations. In transmen, increase in grip strength was associated with increase in lean body mass (per kg increase in grip strength: $+0.010 \mathrm{~kg}, 95 \% \mathrm{Cl}+0.003 ;+0.017$ ), while this was not found in transwomen (per $\mathrm{kg}$ increase in grip strength: $+0.004 \mathrm{~kg}, 95 \% \mathrm{Cl}-0.000 ;+0.009)$. Change in grip strength was not associated with change in BMD in transwomen and transmen.

Conclusions: After 1 year of HT, grip strength decreased in transwomen, and increased in transmen. In transmen only, change in grip strength was associated with change in lean body mass.
\end{abstract}

\section{Key Words}

- transgender

- gender-affirming hormonal treatment

- grip strength

- muscle mass

\section{Introduction}

According to the DSM criteria, gender dysphoria (GD) is defined as the incongruence between a person's assigned sex at birth and the experienced gender (1). GD often has a strong impact on the person's psychological wellbeing. Therefore, most trans people prefer treatment to change physical appearance, for example gender-affirming hormonal treatment (HT) with or without genderaffirming surgery.

Grip strength and muscle mass are good indications of the masculinity of the body. A decrease in grip strength and muscle mass could lead to a more feminine body for transwomen (male-to-female trans people),

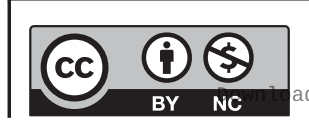

This work is licensed under a Creative Commons Attribution-NonCommercial 4.0 International License. ded from Bioscientifica.com at 04/26/2023 07:12:44AM 
while an increase in grip strength and muscle mass indicates a more masculine body for transmen (femaleto-male trans people). Besides the importance of physical appearance, a change in grip strength and muscle mass also might be important in the prevention of sarcopenia (the age-related loss of muscle mass) (2) and dynapenia (the age-related loss of muscle strength) (3).

Earlier studies on effects of HT in trans people focused on bone mineral density (BMD) and body composition. These studies found an increase in lean body mass in transmen and a decrease in lean body mass in transwomen $(4,5)$. BMD increased in both transwomen and transmen (6). A study in cis gender people found grip strength to be a predictor of bone mass (7). Possibly, a change in BMD in trans people is associated with a change in grip strength. Some studies described the change in grip strength $(8$, 9); however, sample sizes of these studies were small and possible influences on these changes, for example age, BMI, administration routes of HT and sex hormone concentrations during HT, have not been studied.

The aim of this study is to investigate the time course of change in grip strength in trans people in the first year of HT, to study possible determinants of this change and to study the reciprocal associations between changes in grip strength, lean body mass (as an approximation of muscle mass) and BMD.

\section{Materials and methods}

\section{Study design and study population}

This study is part of the European Network for the Investigation of Gender Incongruence (ENIGI) study, a multicenter prospective cohort study, including treatment centers in Amsterdam, Ghent, Oslo and Florence using the same treatment protocol. The study design is published previously $(10,11)$ and the study is registered at https:// clinicaltrials.gov/ct2/show/NCT01072825. In short, people were included from 2010 until April 2016. The included people were 18 years and older and gave informed consent. People could participate in this study when they started with HT, if they did not use gender-affirming hormones before the start of HT, and if they spoke the native language. During the first year of treatment, the people were seen every 3 months. For the current study, only data from Amsterdam, Ghent and Oslo were analyzed, as grip strength was not assessed in Florence. People were included if their grip strength was measured at baseline and after 12 months. For the analyses on lean body mass and BMD, people were included if a dual-energy X-ray absorptiometry (DXA) was performed at baseline (range 4 months before to 4 months after baseline) and after 12 months (range 10-14 months) of HT. People from Oslo were excluded from the analyses on lean body mass and $\mathrm{BMD}$, because a different type of DXA scanner was used (Oslo: Lunar (GE Lunar, Madison, WI, USA); Amsterdam and Ghent: Hologic Discovery A (Hologic Inc, Bedford, MA, USA)). In total, 1017 participants were included in the overall study. After exclusions due to unknown grip strength values at baseline or 12 months $(n=60)$, a follow-up of less than 1 year $(n=363)$ or lost to follow-up $(n=57)$, a total of 249 transwomen and 278 transmen were included in our analyses (Fig. 1).

Transwomen were treated with the anti-androgen cyproterone acetate (CPA) $50 \mathrm{mg}$ daily, in combination with $2-4 \mathrm{mg}$ oral estradiol valerate a day or $100 \mu \mathrm{g} / 24 \mathrm{~h}$ estradiol patch twice a week. People older than 40 years were advised to be treated with transdermal estrogens, because of thrombosis risk (12). Transmen were treated with testosterone. They could choose between testosterone gel (50 $\mathrm{mg}$ daily), testosterone esters (250 $\mathrm{mg}$ intramuscular every $2-3$ weeks) or testosterone undecanoate $(1000 \mathrm{mg}$ intramuscular every 12 weeks).

The Medical Ethics Review Committee of Ghent approved the study protocol. Local Ethical Review Committees approved participations in the other centers.

\section{Clinical data collection}

Grip strength was measured in kilograms (kg), using an adjustable hand-held standard grip device, a Jamar Dynamometer $(10,13)$. The grip strength of the dominant hand was measured twice and the highest value was noted. These measurements were performed at baseline and after 3 months, 6 months, 9 months and 12 months of HT. However, from Oslo only data at baseline and after 12 months were available.

Body weight and height were measured at every visit. People were measured without shoes and in light indoor clothes. BMI was calculated by weight divided by the square of body height.

\section{DXA}

A whole-body DXA was performed to measure lean body mass of the arms and the legs. Outcomes of body composition were determined using manufacturersupplied algorithms. The specific arm and leg regions were defined with software from Hologic.

Absolute BMD values were obtained for lumbar spine (L1-L4, LS), total hip (TH) and femoral neck (FN).

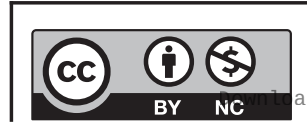




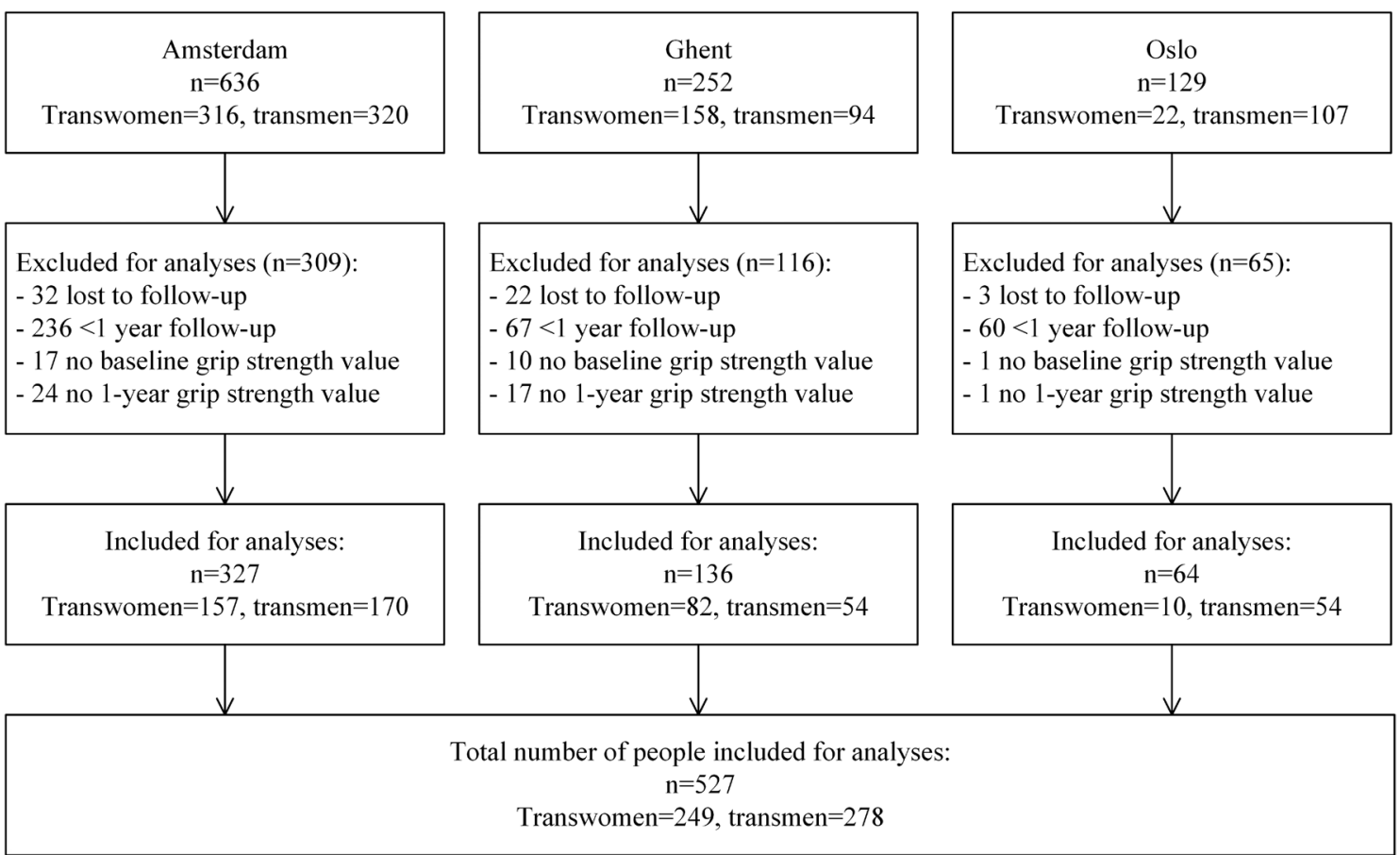

Figure 1

Inclusion flowchart.

The same type of DXA device was used in Amsterdam and Ghent (Hologic Discovery A, Hologic Inc., MA, USA) and software version 13.5 .3 was used.

\section{Laboratory measurements}

Venous blood samples were obtained in the morning at baseline, after 3 months of HT and after 12 months of HT. As the results were also used during clinical care, assays with higher quality were implemented when they were available. In order to compare the new and old values likewise, conversion formulas were generated by the endocrine laboratory.

In Oslo, testosterone and estradiol were determined using a competitive immunoassay (ECLIA, Roche Diagnostic) with a lower limit of quantitation (LOQ) of $0.1 \mathrm{nmol} / \mathrm{L}(2.6 \mathrm{ng} / \mathrm{dL})$ and $18.4 \mathrm{pmol} / \mathrm{L}(5.0 \mathrm{pg} / \mathrm{mL})$, and a coefficient of variation (CV) of 5 and 7\%, respectively. In Ghent, an E170 Modular (E2 Gen II, Roche Diagnostics) was used for testosterone (LOQ $0.4 \mathrm{nmol} / \mathrm{L}(11.5 \mathrm{ng} / \mathrm{dL})$, CV 2.6\%) and estradiol (LOQ 92 pmol/L (25.1 pg/mL), CV 3.2\%). For estradiol, it was updated in March 2015 to an E170 Modular (E2 Gen III, Roche Diagnostics) with a conversion formula of Gen III $=6.687940+0.834495 \times$ Gen II. In Amsterdam, estradiol was measured using a competitive immunoassay (Delfia, PerkinElmer, Wallac Oy, Turku, Finland) with a LOQ of $20 \mathrm{pmol} / \mathrm{L}(5.4 \mathrm{pg} / \mathrm{mL})$ and a CV of $<13 \%$ until July 2014. Thereafter, an LC-MS/MS (VUmc, Amsterdam, the Netherlands; LOQ 20 pmol/L (5.4 pg/mL), CV <7\%) was used, with a conversion formula of LC-MS/MS $=1.60 \times$ Delfia-29. Testosterone was measured using a radioimmunoassay (RIA, Coat-A-Count, Siemens, Los Angeles, CA, USA; LOQ $1 \mathrm{nmol} / \mathrm{L}$ (28.8 ng/dL), CV $<10 \%$ ) until January 2013. After that, it was measured using a competitive immunoassay (Gen III, Architect, Abbott, Abbott Park, IL, USA) with a LOQ of $0.1 \mathrm{nmol} / \mathrm{L}$ $(2.9 \mathrm{ng} / \mathrm{dL})$ and a $\mathrm{CV}<10 \%$. Two conversion formulas were generated: $<8 \mathrm{nmol} / \mathrm{L}$ : Architect $=1.1 \times \mathrm{RIA}+0.2$; $>8 \mathrm{nmol} / \mathrm{L}:$ Architect $=1.34 \times$ RIA-1.65.

\section{Statistical analyses}

Results are presented as mean with standard deviation (s.D.) in case of normal distribution, or median with interquartile range (IQR) for non-normally distributed data, and percentages. In case of non-normally distributed data, a log transformation was performed before further analyses.

To examine the course of the change in grip strength during the first year, linear mixed model analyses were performed. The influence of age, differences in BMI, different administration routes of HT and serum hormone concentrations, were analyzed. Age was divided into groups ( $<25$ years, $25-40$ years, $\geq 40$ years), to stratify for accrual of grip strength, peak grip strength and

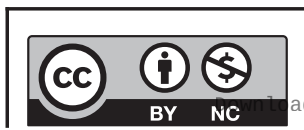

This work is licensed under a Creative Commons Attribution-NonCommercial 4.0 International License. ded from Bioscientifica.com at 04/26/2023 07:12:44AM 
age-related decrease of grip strength. BMI was defined as underweight $\left(<18.5 \mathrm{~kg} / \mathrm{m}^{2}\right)$, normal weight $\left(18.5-25 \mathrm{~kg} / \mathrm{m}^{2}\right)$ and overweight $\left(\geq 25 \mathrm{~kg} / \mathrm{m}^{2}\right)$. For analyses between differences in the administration route of HT, people who used the same administration route for at least 9 months were included. Mean concentrations of estradiol and testosterone during HT were calculated by averaging the results of the measurements after 3 and after 12 months of HT. As different assays were used in the centers to determine estradiol and testosterone and no conversion formulas between the centers were available, it was not possible to analyze the estradiol and testosterone concentrations as absolute values. Therefore, centerspecific tertiles were created for estradiol and testosterone and were thereafter analyzed together. The center-specific mean estradiol concentrations in transwomen were first tertile $122 \mathrm{pmol} / \mathrm{L}(33 \mathrm{pg} / \mathrm{mL}$, Amsterdam), $159 \mathrm{pmol} / \mathrm{L}$ (43 pg/mL, Ghent) and $167 \mathrm{pmol} / \mathrm{L}(46 \mathrm{pg} / \mathrm{mL}$, Oslo); second tertile $233 \mathrm{pmol} / \mathrm{L}(63 \mathrm{pg} / \mathrm{mL}$, Amsterdam), $248 \mathrm{pmol} / \mathrm{L}(68 \mathrm{pg} / \mathrm{mL}$, Ghent) and $317 \mathrm{pmol} / \mathrm{L}(83 \mathrm{pg} / \mathrm{mL}$, Oslo); and third tertile $405 \mathrm{pmol} / \mathrm{L}$ (110pg/mL, Amsterdam), $572 \mathrm{pmol} / \mathrm{L} \quad(156 \mathrm{pg} / \mathrm{mL}$, Ghent $)$ and $398 \mathrm{pmol} / \mathrm{L}$ (108 pg/mL, Oslo). The center-specific mean testosterone concentrations for transmen were first tertile: $16 \mathrm{nmol} / \mathrm{L}$ (461 ng/dL, Amsterdam), $10 \mathrm{nmol} / \mathrm{L}$ ( $288 \mathrm{ng} / \mathrm{dL}$, Ghent) and $15 \mathrm{nmol} / \mathrm{L}$ ( $432 \mathrm{ng} / \mathrm{dL}$, Oslo); second tertile: $28 \mathrm{nmol} / \mathrm{L}$ (806ng/dL, Amsterdam), $16 \mathrm{nmol} / \mathrm{L}$ (461 ng/dL, Ghent) and $21 \mathrm{nmol} / \mathrm{L}(605 \mathrm{ng} / \mathrm{dL}$, Oslo); and third tertile: $54 \mathrm{nmol} / \mathrm{L}$ (1555 ng/dL, Amsterdam), $24 \mathrm{nmol} / \mathrm{L}$ (691 ng/dL, Ghent) and $33 \mathrm{nmol} / \mathrm{L}$ (950 ng/dL, Oslo).

The average of the right and left arm was calculated for the analyses on the lean body mass of the arms, and the average of the right and left leg was calculated to analyze the lean body mass of the legs. To evaluate the change of grip strength, lean body mass, BMD, and serum creatinine after 1 year, the absolute and percentage difference between the baseline values and the values after 12 months were calculated. As these were normal distributed variables, linear regression analyses were performed to calculate the mean and 95\% CI.

To study the association between changes in grip strength and changes in lean body mass, BMD or creatinine concentrations, linear regression analyses were performed.

All analyses were performed separately for transwomen and transmen. Data were analyzed using STATA Statistical Software (Statacorp, version 15.1). $P$ values $<0.050$ were considered statistically significant.

\section{Results}

\section{Characteristics}

The characteristics are shown in Table 1. No differences were found between included and excluded people in

Table 1 Characteristics of the study population.

\begin{tabular}{l}
\hline \\
\hline Age, years \\
BMI, kg/m² \\
Smoking (\% yes) \\
Alcohol (\% yes) \\
Grip strength (kg) \\
Creatinine ( $\mu$ mol/L) \\
Hormone administration route ${ }^{a}$ \\
Estradiol oral \\
Estradiol transdermal \\
Testosterone gel \\
Testosterone undecanoate i.m. \\
Testosterone esters i.m. \\
Estradiol concentrations, pmol/L \\
Amsterdam \\
Ghent \\
Oslo \\
Testosterone concentrations, nmol/L \\
Amsterdam \\
Ghent \\
Oslo
\end{tabular}

\begin{tabular}{c}
\hline \multicolumn{1}{c}{ Transwomen } \\
\hline Baseline \\
\hline $28(23-40)$ \\
$23.8(4.5)$ \\
24.7 \\
44.8 \\
$41.8(8.9)$ \\
$78.5(10.8)$ \\
- \\
- \\
- \\
- \\
$105(83-131)$ \\
$109(88-130)$ \\
$120(100-140)$ \\
$18.5(14.0-23.0)$ \\
$17.9(13.5-21.5)$ \\
$18.1(12.2-20.4)$
\end{tabular}

\begin{tabular}{c}
$(n=249)$ \\
\hline During HT \\
\hline $24.5(4.4)$ \\
14.7 \\
44.6 \\
$40.0(8.9)$ \\
$73.1(10.6)$
\end{tabular}

\begin{tabular}{|c|c|}
\hline \multicolumn{2}{|c|}{ Transmen $(n=278)$} \\
\hline Baseline & During HT \\
\hline $23(20-30)$ & \\
\hline $25.5(5.6)$ & $25.9(4.8)$ \\
\hline 29.9 & 19.9 \\
\hline 55.3 & 55.8 \\
\hline $33.1(6.5)$ & $39.2(6.8)$ \\
\hline
\end{tabular}

Data are presented as median with inter quartile range, mean with standard deviation, percentages or absolute numbers. anly in people who used the same hormone administration route for $>75 \%$ of the follow-up time.

134

86

$-$

225 (141-329)

246 (181-342)

257 (195-325)

$0.8(0.6-0.9)$

$0.7(0.5-1.1)$

$0.4(0.4-0.6)$
-

$-$

$-$

$-$

142 (59-371)

166 (116-431)

280 (180-480)

$1.3(1.0-1.7)$

$1.0(0.7-1.3)$

$1.0(0.8-1.3)$
$77.4(10.6)$

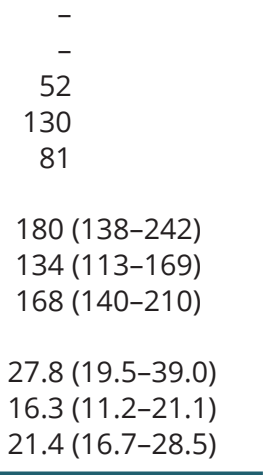


baseline grip strength, age, BMI, estradiol concentrations, testosterone concentrations or smoking habits (Supplementary Table 1, see section on supplementary data given at the end of this article).

For the analyses on lean body mass, 171 transwomen and 154 transmen were included. For these analyses, excluded transwomen were younger (median age 26 years, IQR 21-34) than included transwomen (median age 31 years, IQR 23-42). Excluded transmen were younger (median age 22 years, IQR 19-25) and had a lower BMI (mean $24.3 \mathrm{~kg} / \mathrm{m}^{2}$, S.D. 5.2 ) than included transmen (median age 28 years, IQR 20-33, and mean BMI $26.0 \mathrm{~kg} / \mathrm{m}^{2}$, s.D. 5.5 ). No differences were found between included and excluded people in baseline grip strength, estradiol concentrations, testosterone concentrations or smoking habits.

For the analyses on LS BMD, 207 transwomen and 229 transmen were included. For TH and FN, 206 transwomen and 216 transmen were included. No differences were found between included and excluded transwomen. Excluded transmen were younger (median age 21 years, IQR 19-25) than included transmen (median age 24 years, IQR 21-31).

\section{Grip strength}

In transwomen, grip strength decreased with $-1.8 \mathrm{~kg}$ (95\% CI $-2.6 ;-1.0)$, while in transmen, grip strength increased with $+6.1 \mathrm{~kg}(95 \% \mathrm{CI}+5.5 ;+6.7)$. The course of the grip strength change over time is shown in Fig. 2. For transwomen, $66 \%$ of the decrease in grip strength $(-1.2 \mathrm{~kg})$ occurred in the last 3 months, while in transmen $49 \%$ of the increase $(+3.0 \mathrm{~kg})$ occurred in the first 3 months. Change in grip strength did not vary between different age groups (Fig. 3A), different BMI groups (Fig. 3B) and different administration routes of HT (Fig. 3C), for both transwomen and transmen. Change in grip strength did not vary between different hormone concentrations, for either transwomen or transmen (Fig. 3D). No analyses on testosterone concentrations in transwomen could be performed, as testosterone was suppressed $(<2 \mathrm{nmol} / \mathrm{L}$, $<58 \mathrm{ng} / \mathrm{dL}$ ) in the majority of the transwomen $(94 \%)$.

\section{Grip strength in relation to lean body mass}

As reported previously in this study population (4), a decrease in lean body mass was observed in transwomen and an increase in lean body mass was observed in transmen during the first year of HT.

Associations of change in grip strength with change in lean body mass are presented in Table 2 . In transwomen,

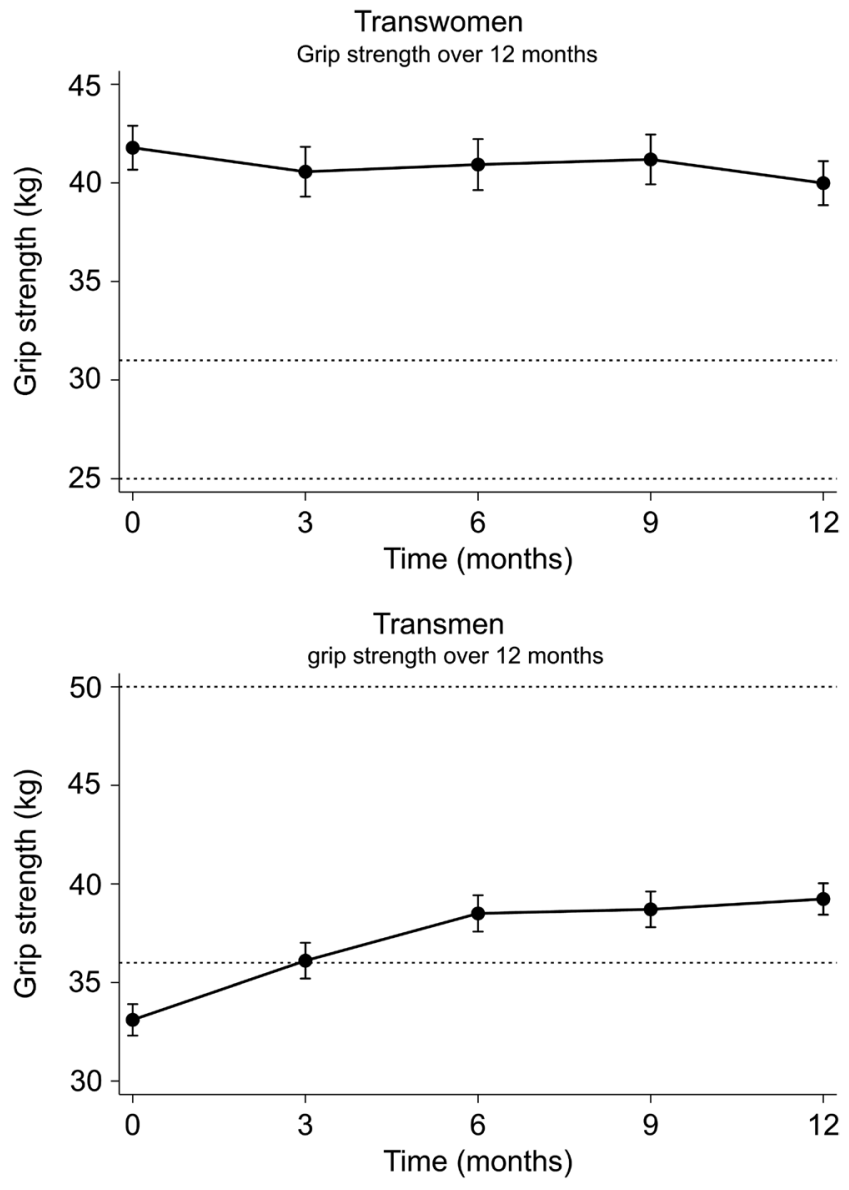

Figure 2

Change in grip strength during the first 12 months of gender-affirming hormonal treatment in transwomen and transmen. Data are presented as means with $95 \% \mathrm{Cl}$. The 25 th and 75 th percentiles of the reference populations are shown with dashed lines. For transwomen the 25th percentile is $25 \mathrm{~kg}$ and the 75th percentile is $31 \mathrm{~kg}$. For transmen the 25th percentile is $36 \mathrm{~kg}$ and the 75th percentile is $50 \mathrm{~kg}(18)$.

no associations between change in grip strength and change in arm or leg lean body mass was seen. In transmen, increase in grip strength was associated with an increase in arm lean body mass (per kg increase in grip strength: $+0.010 \mathrm{~kg}, 95 \% \mathrm{CI}+0.003 ;+0.017)$, but not with change in leg lean body mass.

\section{Grip strength in relation to BMD}

As reported previously in this study population (6), increases in LS BMD, TH BMD and FN BMD were observed in transwomen, and increases in LS BMD and TH BMD, but not FN BMD, were observed in transmen during the first year of HT.

The associations of change in grip strength with change in BMD are shown in Table 2 . 
$\underline{\text { Transwomen }}$

A

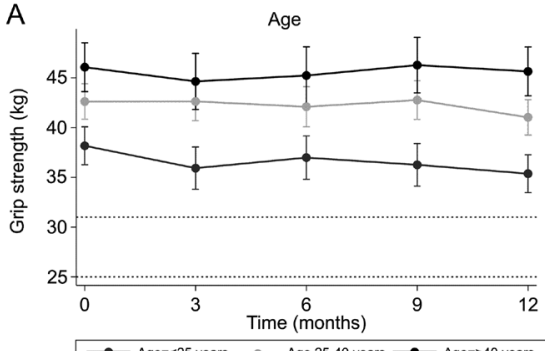

$\longrightarrow$ Age $=<25$ years $\longrightarrow$ Age $25-40$ years $\longrightarrow$ Age $=>40$ years

B

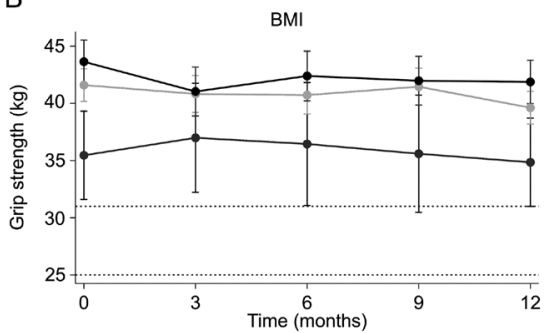

C

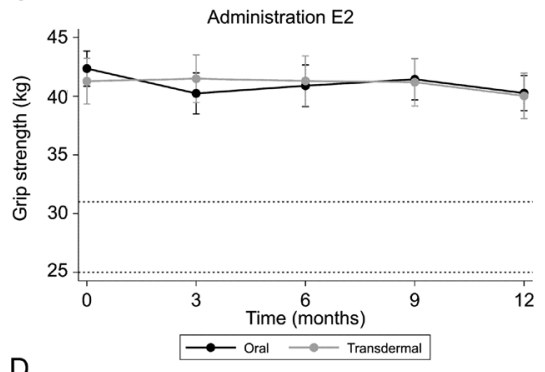

D

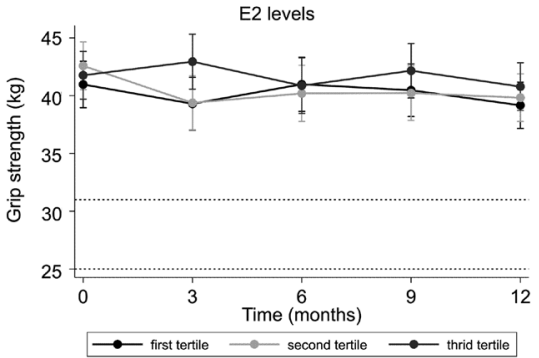

$\underline{\text { Transmen }}$

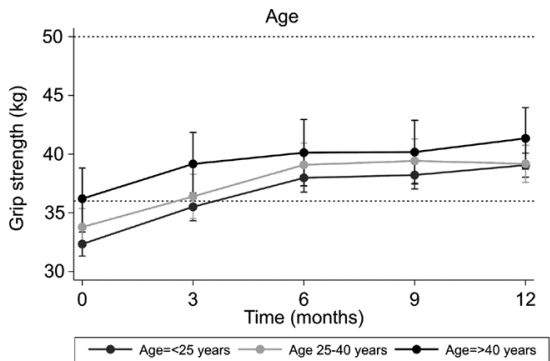

BMI
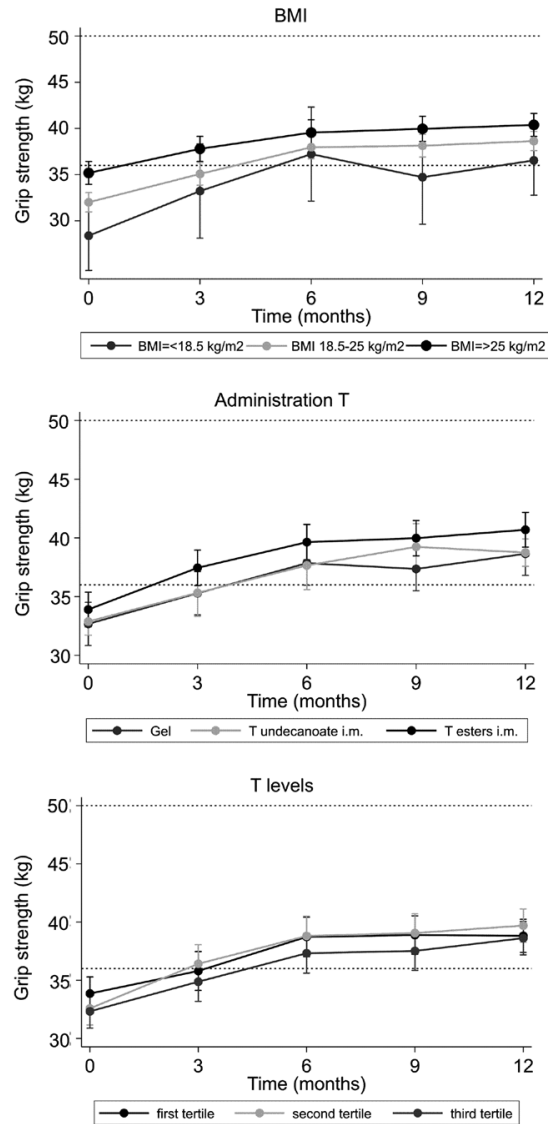

Figure 3

Differences in change in grip strength for age groups, BMI groups, routes of hormonal administration, estradiol concentrations and testosterone concentrations. Data are presented as means with $95 \% \mathrm{Cls}$. Reference values (25th and 75th percentile) are based on the mean age of this population. For transwomen the 25th percentile is $25 \mathrm{~kg}$ and the 75 th percentile is $31 \mathrm{~kg}$. For transmen the 25th percentile is $36 \mathrm{~kg}$ and the 75th percentile is $50 \mathrm{~kg}$ (18). (A) Grip strength change over 12 months between age, adjusted for administration route. (B) Grip strength change over 12 months between BMI groups. (C) Grip strength change over 12 months between different administration routes, adjusted for age. (D) Grip strength change over 12 months between different hormone concentrations.

Table 2 Associations between change in grip strength (per kg increase) and lean body mass, bone mineral density and creatinine, separately for transwomen and transmen.

\begin{tabular}{|c|c|c|}
\hline & \multicolumn{2}{|l|}{ Transwomen } \\
\hline & Mean change $(95 \% \mathrm{Cl})$ & $P$ value \\
\hline \multicolumn{3}{|l|}{ Lean body mass } \\
\hline Arm & $+0.004 \mathrm{~kg}(-0.000 ;+0.009)$ & 0.079 \\
\hline Leg & $+0.009 \mathrm{~kg}(-0.003 ;+0.021)$ & 0.161 \\
\hline \multicolumn{3}{|c|}{ Bone mineral density } \\
\hline Lumbar spine & $+0.02 \%(-0.05 ;+0.10)$ & 0.556 \\
\hline Total hip & $+0.05 \%(-0.01 ;+0.10)$ & 0.112 \\
\hline Femoral neck & $+0.05 \%(-0.03 ;+0.12)$ & 0.201 \\
\hline Creatinine & $-0.1 \mu \mathrm{mol} / \mathrm{L}(-0.2 ;+0.1)^{\mathrm{a}}$ & 0.535 \\
\hline
\end{tabular}

\begin{tabular}{ccc}
\hline \multicolumn{2}{c}{ Transmen } & \\
\hline Mean change $(95 \% \mathrm{Cl})$ & & $P$ value \\
\hline & & \\
$+0.010 \mathrm{~kg}(+0.003 ;+0.017)$ & & 0.003 \\
$+0.014 \mathrm{~kg}(-0.002 ;+0.030)$ & & 0.078 \\
& & 0.900 \\
$+0.01 \%(-0.08 ;+0.09)$ & & 0.630 \\
$-0.02 \%(-0.09 ;+0.05)$ & & 0.401 \\
$+0.04 \%(-0.06 ;+0.15)$ & & 0.035 \\
\hline
\end{tabular}

aData shown is per kg decrease in grip strength.

https://ec.bioscientifica.com https://doi.org/10.1530/EC-19-0196 (c) 2019 The authors Published by Bioscientifica Ltd
This work is licensed under a Creative Commons Attribution-NonCommercial 4.0 International License. ded from Bioscientifica.com at 04/26/2023 07:12:44AM 
Change in grip strength was not associated with change in BMD in both transwomen and transmen.

\section{Grip strength in relation to creatinine}

Serum creatinine concentrations decreased with $-5.0 \mu \mathrm{mol} / \mathrm{L}(95 \% \mathrm{CI}-6.2 ;-3.8)$ in transwomen and increased with $+11.1 \mu \mathrm{mol} / \mathrm{L}(95 \% \mathrm{CI}+10.1 ;+12.2)$ in transmen. The associations of change in grip strength with change in creatinine are described in Table 2 . In transmen, the increase in creatinine was associated with an increase in grip strength (per $\mathrm{kg}$ increase in grip strength: $+0.2 \mu \mathrm{mol} / \mathrm{L}, 95 \% \mathrm{CI}+0.0 ;+0.4)$. In transwomen, a decrease in creatinine tended to be associated with a decrease in grip strength (per kg decrease in grip strength: $-0.1 \mu \mathrm{mol} / \mathrm{L}, 95 \% \mathrm{CI}-0.2 ;+0.1)$.

\section{Discussion}

In transwomen, a decrease in grip strength after 1 year of HT was found, while in transmen, an increase in grip strength after 1 year of HT was found. These changes were also found in the serum creatinine concentrations. Grip strength change did not vary between age groups, BMI groups, administration routes and different hormone concentrations, for neither transwomen nor transmen. Change in grip strength was associated with change in lean body mass in transmen but not in transwomen. Change in grip strength was not associated with a change in BMD.

In our study, transwomen decreased in grip strength, possibly due to the lack of testosterone. This is in agreement with a study in young men using gonadotropinreleasing hormone agonists, which found that muscle mass decreased by approximately $1 \mathrm{~kg}$ after 10 weeks (14). The finding of an increase in grip strength in transmen is consistent with results from studies about testosterone replacement in hypogonadal men (15). Testosterone has an effect on myoblast proliferation and myoblast differentiation, and testosterone increases the number of satellite cells, which promotes protein synthesis of muscle mass (16). Thus, testosterone plays an important role in muscle mass and muscle strength. Accordingly, testosterone is not only important for muscle in men, but also for muscle in women. This is among others important for the prevention of dynapenia in older people.

The largest decrease in grip strength for transwomen took place in the last 3 months of HT, while the largest change for transmen took place in the first 3 months.
The change in transmen is in line with a randomized controlled trial that shows an increase in strength in the first 6 months, after the use of testosterone in healthy men $\geq 60$ years old (17). Interestingly, the time difference of the slow loss of grip strength in transwomen and the fast increase in transmen is opposite of what is observed for strength with training and detraining. It might possibly take longer for muscles to decrease in proteins due to lack of testosterone, than it is to increase due to administration of testosterone. However, to fully understand the difference, more research is necessary. After 12 months, the median grip strength of transwomen still falls into the 95th percentile for age-matched females. The median grip strength of transmen after 12 months falls into the 25th percentile of age-matched males (18). Thus, transwomen are still stronger than average females and transmen are still weaker than average males. However, as this study is a follow-up of 12 months, transwomen and transmen might attain a grip strength value closer to the reference values of, respectively, females and males after a longer duration of HT. No difference was found for grip strength change between age groups, BMI groups and administration routes. A larger decrease in transwomen and a smaller increase in transmen was expected at age $\geq 40$ years, because of the age-related decrease of grip strength in combination with the lack of testosterone. However, our study population of $\geq 40$ years was not very old (mean age 49 years for transwomen and 47 years for transmen). Furthermore, our study suggests that change in grip strength was not related to mean serum hormone concentrations during the first year of HT. This finding is line with a study on endocrine determinants in sarcopenia in 518 men aged 40-79 years, which found no association between total and bioavailable testosterone and the annual change in grip strength in men, after a follow-up of 4.3 years (19). The finding that concentrations of testosterone and estradiol were not associated with the change in grip strength can be used to inform trans people that a higher dosage does not lead to a larger increase or decrease in grip strength. Also, because no relationship was found between change in grip strength and administration routes, trans people can make a more well-informed decision when choosing between administration routes.

In transwomen, no association was found between change in lean body mass and change in grip strength, while it was only weakly associated in transmen. This is in contrast to a large cross-sectional and longitudinal perspective study of 847 participants aged 20-100 years, which found a strong correlation between grip strength and lean body mass (20). However, this correlation was

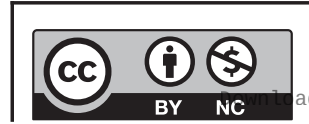

This work is licensed under a Creative Commons Attribution-NonCommercial 4.0 International License. ed from Bioscientifica.com at 04/26/2023 07:12:44AM 
age dependent, and it was the strongest at 60 years old. People younger than 60 years appeared to be stronger than predicted with muscle mass and people older than 60 years appeared to be weaker. They also showed a stronger correlation between age and grip strength compared to age and muscle mass. Our population has a mean age of 25 years, this is significantly younger than 60 years, thus the correlation might be lower. Furthermore, change in grip strength was not associated to change in $\mathrm{BMD}$. Therefore, change in BMD cannot be predicted by change in grip strength.

This is a large, multicenter, prospective study. Standardized measurements were used to measure grip strength, and there is a widespread age range. To our knowledge, this is the first study that describes the change in grip strength over the course of a year and that examines possible influences on this change. However, our study also had some limitations. First, data about physical activity were only available in smaller subgroup of the study population and was therefore not analyzed. Therefore, we could miss data that can partially explain the change in grip strength. However, in previous studies, no change in physical activity was found in transwomen (8) and transmen (9) during the first year of HT. Second, possibly a true impact of testosterone concentrations on grip strength cannot be detected, since circulating testosterone concentrations were evaluated, instead of available testosterone in muscle cells (21). In addition, the laboratory measurements were performed differently at the study centers and changed in two sites during follow-up. Although conversion formulas were generated and tertiles were used instead of absolute values, it might be that the variability in hormone concentrations affected the results. Lastly, it is questionable whether a decrease in grip strength in transwomen of almost $2 \mathrm{~kg}$ is clinically relevant. Nonetheless, transwomen possibly feel more feminine due to the decrease in muscle mass $(22,23)$. One study reported on the desired effects of HT in transwomen in Indonesia, including reduced muscle mass (23). A study in associations among masculinity, strength and attractiveness shows a positive correlation between masculinity and grip strength, and a negative correlation between masculinity and attractiveness in young women (24). This might indicate that a decrease in grip strength in women could influence the feeling of attractiveness. However, this may be dissimilar in transwomen. A questionnaire for transwomen and transmen would be of interest to investigate a possible satisfaction with the change in grip strength.

In conclusion, grip strength decreases in transwomen and increases in transmen, after 12 months of HT.
This is interesting for the prevention of sarcopenia and dynapenia, since testosterone has a positive effect on muscle mass and grip strength. In addition, knowing the effects of HT on grip strength, its association with hormone concentrations and hormonal administration routes, and its relation with change in muscle mass and $\mathrm{BMD}$, can help care providers and trans people with their expectations of HT. For further research, it would be interesting to evaluate the subjective satisfaction related to changes in grip strength and to evaluate the change of grip strength after a longer follow-up to see if the grip strength will reach the grip strength reference values for women or men, for transwomen and transmen, respectively.

\section{Supplementary data}

This is linked to the online version of the paper at https://doi.org/10.1530/ EC-19-0196.

\section{Declaration of interest}

The authors declare that there is no conflict of interest that could be perceived as prejudicing the impartiality of the research reported.

\section{Funding}

This research did not receive any specific grant from any funding agency in the public, commercial or not-for-profit sector.

\section{References}

1 Cohen-Kettenis PT \& Pfafflin F. The DSM diagnostic criteria for gender identity disorder in adolescents and adults. Archives of Sexual Behavior 201039 499-513. (https://doi.org/10.1007/s10508-0099562-y)

2 Walston JD. Sarcopenia in older adults. Current Opinion in Rheumatology 201224 623-627. (https://doi.org/10.1097/ BOR.0b013e328358d59b)

3 Clark BC \& Manini TM. What is dynapenia? Nutrition 201228 495-503. (https://doi.org/10.1016/j.nut.2011.12.002)

4 Klaver M, de Blok CJM, Wiepjes CM, Nota NM, Dekker MJHJ, de Mutsert R, Schreiner T, Fisher AD, T'Sjoen G \& den Heijer M. Changes in regional body fat, lean body mass and body shape in trans persons using cross-sex hormonal therapy: results from a multicenter prospective study. European Journal of Endocrinology 2018 178 163-171. (https://doi.org/10.1530/EJE-17-0496)

5 Wierckx K, Van Caenegem E, Schreiner T, Haraldsen I, Fisher AD, Toye K, Kaufman JM \& T'Sjoen G. Cross-sex hormone therapy in trans persons is safe and effective at short-time follow-up: results from the European network for the investigation of gender incongruence. Journal of Sexual Medicine 201411 1999-2011. (https:// doi.org/10.1111/jsm.12571)

6 Wiepjes CM, Vlot MC, Klaver M, Nota NM, de Blok CJ, de Jongh RT, Lips P, Heijboer AC, Fisher AD, Schreiner T, et al. Bone mineral density increases in trans persons after 1 year of hormonal treatment: a multicenter prospective observational study. Journal of Bone and Mineral Research 201732 1252-1260. (https://doi.org/10.1002/ jbmr.3102)

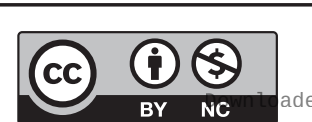

This work is licensed under a Creative Commons Attribution-NonCommercial 4.0 International License. Aed from Bioscientifica com at 04/26/2023 07:12:44AM 
7 Chan DC, Lee WT, Lo DH, Leung JC, Kwok AW \& Leung PC. Relationship between grip strength and bone mineral density in healthy Hong Kong adolescents. Osteoporosis International 200819 1485-1495. (https://doi.org/10.1007/s00198-008-0595-1)

8 Van Caenegem E, Wierckx K, Taes Y, Schreiner T, Vandewalle S, Toye K, Kaufman JM \& T'Sjoen G. Preservation of volumetric bone density and geometry in trans women during cross-sex hormonal therapy: a prospective observational study. Osteoporosis International 201526 35-47. (https://doi.org/10.1007/s00198-014-2805-3)

9 Van Caenegem E, Wierckx K, Taes Y, Schreiner T, Vandewalle S, Toye K, Lapauw B, Kaufman JM \& T'Sjoen G. Body composition, bone turnover, and bone mass in trans men during testosterone treatment: 1-year follow-up data from a prospective case-controlled study (ENIGI). European Journal of Endocrinology 2015172 163-171. (https://doi.org/10.1530/EJE-14-0586)

10 Dekker MJHJ, Wierckx K, Van Caenegem E, Klaver M, Kreukels BP, Elaut E, Fisher AD, van Trotsenburg MAA, Schreiner T, den Heijer M, et al. A European Network for the investigation of gender incongruence: endocrine part. Journal of Sexual Medicine 201613 994-999. (https://doi.org/10.1016/j.jsxm.2016.03.371)

11 Kreukels BP, Haraldsen IR, De Cuypere G, Richter-Appelt H, Gijs L $\&$ Cohen-Kettenis PT. A European network for the investigation of gender incongruence: the ENIGI initiative. European Psychiatry 2012 27 445-450. (https://doi.org/10.1016/j.eurpsy.2010.04.009)

12 Asscheman H, Gooren LJG \& Eklund PLE. Mortality and morbidity in transsexual patients with cross-gender hormone treatment. Metabolism: Clinical and Experimental 198938 869-873. (https://doi. org/10.1016/0026-0495(89)90233-3)

13 Muhldorfer-Fodor M, Ziegler S, Harms C, Neumann J, Cristalli A, Kalpen A, Kundt G, Mittlmeier T \& Prommersberger KJ. Grip force monitoring on the hand: manugraphy system versus Jamar dynamometer. Archives of Orthopaedic and Trauma Surgery 2014134 1179-1188. (https://doi.org/10.1007/s00402-014-2027-3)

14 Bhasin S, Woodhouse L, Casaburi R, Singh AB, Bhasin D, Berman N, Chen X, Yarasheski KE, Magliano L, Dzekov C, et al. Testosterone dose-response relationships in healthy young men. American Journal of Physiology: Endocrinology and Metabolism 2001281 E1172-E1181. (https://doi.org/10.1152/ajpendo.2001.281.6.E1172)

15 Bhasin S, Storer TW, Berman N, Yarasheski KE, Clevenger B, Phillips J, Lee WP, Bunnell TJ \& Casaburi R. Testosterone replacement increases fat-free mass and muscle size in hypogonadal men. Journal of Clinical Endocrinology and Metabolism 199782 407-413. (https:// doi.org/10.1210/jcem.82.2.3733)

16 Brown M. Skeletal muscle and bone: effect of sex steroids and aging. Advances in Physiology Education 200832 120-126. (https://doi. org/10.1152/advan.90111.2008)

17 Storer TW, Basaria S, Traustadottir T, Harman SM, Pencina K, Li Z, Travison TG, Miciek R, Tsitouras P, Hally K, et al. Effects of testosterone supplementation for 3 years on muscle performance and physical function in older men. Journal of Clinical Endocrinology and Metabolism 2017102 583-593. (https://doi.org/10.1210/jc.20162771)

18 Wong SL. Grip strength reference values for Canadians aged 6 to 79 : Canadian Health Measures Survey, 2007 to 2013. Health Reports 2016 27 3-10.

19 Gielen E, O'Neill TW, Pye SR, Adams JE, Wu FC, Laurent MR, Claessens F, Ward KA, Boonen S, Bouillon R, et al. Endocrine determinants of incident sarcopenia in middle-aged and elderly European men. Journal of Cachexia, Sarcopenia and Muscle 20156 242-252. (https://doi.org/10.1002/jcsm.12030)

20 Kallman DA, Plato CC \& Tobin JD. The role of muscle loss in the age-related decline of grip strength: cross-sectional and longitudinal perspectives. Journal of Gerontology 199045 M82-M88. (https://doi. org/10.1093/geronj/45.3.M82)

21 Roy TA, Blackman MR, Harman SM, Tobin JD, Schrager M \& Metter EJ. Interrelationships of serum testosterone and free testosterone index with FFM and strength in aging men. American Journal of Physiology: Endocrinology and Metabolism 2002283 E284-E294. (https://doi.org/10.1152/ajpendo.00334.2001)

22 Gorin-Lazard A, Baumstarck K, Boyer L, Maquigneau A, Gebleux S, Penochet JC, Pringuey D, Albarel F, Morange I, Loundou A, et al. Is hormonal therapy associated with better quality of life in transsexuals? A cross-sectional study. Journal of Sexual Medicine 2012 9 531-541. (https://doi.org/10.1111/j.1743-6109.2011.02564.x)

23 Idrus NI \& Hymans TD. Balancing benefits and harm: chemical use and bodily transformation among Indonesia's transgender waria. International Journal on Drug Policy 201425 789-797. (https://doi. org/10.1016/j.drugpo.2014.06.012)

24 Van Dongen S. Associations among facial masculinity, physical strength, fluctuating asymmetry and attractiveness in young men and women. Annals of Human Biology 201441 205-213. (https://doi. org/10.3109/03014460.2013.847120)

Received in final form 18 June 2019

Accepted 26 June 2019

Accepted Preprint published online 26 June 2019 https://ec.bioscientifica.com

https://doi.org/10.1530/EC-19-0196 (c) 2019 The authors Published by Bioscientifica Ltd

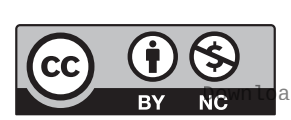

This work is licensed under a Creative Commons Attribution-NonCommercial 4.0 International License. ded from Bioscientifica.com at 04/26/2023 07:12:44AM 